\title{
A comparison of extracorporeal shock wave therapy, physiotherapy, and local steroid injection in treatment of lateral epicondylitis
}

\author{
Lateral epikondilit tedavisinde ekstrakorporeal şok dalga tedavisi, fizyoterapi ve lokal steroid \\ enjeksiyonunun karşılaştırılması
}

Soner Akkurt, ${ }^{1}$ Ahmet Yllmaz, ${ }^{2}$ Tolga Saka ${ }^{3}$

${ }^{1}$ Erciyes Üniversitesi Tıp Fakültesi, Spor Hekimliği Anabilim Dall, Kayseri, Türkiye

${ }^{2}$ Bafra Devlet Hastanesi, Fiziksel Tip ve Rehabilitasyon Kliniği, Samsun, Türkiye

${ }^{3}$ Bezmialem Vakıf Üniversitesi Tıp Fakültesi, Spor Hekimliği Anabilim Dalı, İstanbul, Türkiye

Geliș tarihi / Received: Aralk 2014 Kabul tarihi / Accepted: Mayıs 2015

$\ddot{O Z Z}$

Amaç: Bu çalışmada lateral epikondilit tedavisinde kullanılan ekstrakorporeal şok dalga tedavisi (ESWT), fizyoterapi ve lokal steroid enjeksiyonunun etkinliği karşılaştırıldı.

Hastalar ve yöntemler: Çalışmaya Ocak 2013 - Aralık 2013 tarihleri arasında klinik olarak lateral epikondilit tanısı konmuş toplam 59 hasta (34 erkek, 25 kadın; ort. yaş 46.4 yıl; dağılım 35-60 yıl) alındı. Hastalar rastgele ESWT (ESWT grubu), lokal steroid enjeksiyonu (E grubu) ve fizyoterapi (FT grubu) olmak üzere üç tedavi grubuna ayrıldı. Tedavi öncesi, tedavi sonrası üçüncü, altıncı ve 12. haftalarda görsel analog ölçeği (GAÖ), el kavrama kuvveti, lateral epikondil üzerine basmakla oluşan duyarlılık testi, Thomson testi ve sandalye kaldırma testleri yapıldı.

Bulgular: Üç tedavi grubunda da GAÖ skorları başlangıca kıyasla üç, altı ve 12. haftalarda azalırken, el kavrama kuvveti arttı. Lateral epikondil üzerine basmakla oluşan duyarlılık, Thomson testi ve sandalye kaldırma test sonuçları başlangıca kıyasla üç, altı ve 12 . haftalarda anlamlı olarak negatifleşti. Başlangıca kıyasla üç, altı ve 12. haftalarda GAÖ skoru ve el kavrama kuvveti skorları açısından tedavi grupları arasında istatistiksel olarak anlamlı bir fark yoktu.

Sonuç: Çalışma sonuçlarımız ESWT, lokal steroid enjeksiyonu ve fizyoterapinin lateral epikondilit tedavisinde 12 haftalık takipte etkili olduğunu göstermektedir.

Anahtar sözcükler: Ekstrakorporeal şok dalga tedavisi; lateral epikondilit; lokal steroid enjeksiyonu; fizyoterapi.

\section{ABSTRACT}

Objectives: This study aims to compare the efficacy of extracorporeal shock wave therapy (ESWT), physiotherapy, and local steroid injection in the treatment of lateral epicondylitis.

Patients and methods: A total of 59 patients (34 males, 25 females; mean age 46.4 years; range 35 to 60 years) who were clinically diagnosed with lateral epicondylitis between January 2013 and December 2013 were included in the study. The patients were randomly divided into three treatment groups as ESWT (ESWT group), local steroid injection (E group) and physiotherapy (FT group). The visual analog scale (VAS), hand grip strength, pressure sensitivity on lateral epicondyle, Thompson test and chair lifting test were performed before treatment and at three, six and 12 weeks following the treatment.

Results: Compared to baseline, VAS scores decreased, while hand grip strength increased in all three treatment groups at three, six, and 12 weeks. Pressure sensitivity with pressure on the lateral epicondyle, Thompson test, and chair lifting test results became significantly negative at three, six, and 12 weeks compared to baseline. There was no statistically significant difference in the VAS and hand grip strength scores at three, six, and 12 weeks compared to baseline among the treatment groups.

Conclusion: Our study results suggest that ESWT, physiotherapy, and local steroid injection are effective in the treatment of lateral epicondylitis during 12 week-follow-up.

Keywords: Extracorporeal shock wave therapy; lateral epicondylitis; local steroid injection; physiotherapy.

İletişim adresi / Corresponding author: Dr. Ahmet Yllmaz. Mimar Sinan Mh., 160. Sk., 4/10 55200 Atakum Samsun, Türkiye.

e-posta / e-mail: ahmetzerrin@gmail.com

Cite this article as:

Akkurt S, Yllmaz A, Saka T. A comparison of extracorporeal shock wave therapy, physiotherapy, and local steroid injection in treatment of lateral epicondylitis. Turk J Phys Med Rehab 2016;62:37-44. 
Lateral epikondilit, 45-54 yaş arası kadın ve erkeklerde sık görülen 'tenisçi dirseği' olarak bilinen bir aşırı kullanım yaralanmasıdır. ${ }^{[1]}$ El bileği ile yapılan tekrarlayıcı dorsifleksiyon aktiviteleri sonucu ekstansör karpi radialis brevis kasının lateral epikondile yapışma yerindeki enflamasyonu ile oluşur. Mikroskopik olarak lateral epikondil bölgesinde yaygın fibrozis, vasküler hiperplazi ve düzensiz kollajen dizilimi eşlik ediyorsa 'lateral dirsek tendinozisi' olarak tanımlanır. ${ }^{[1]}$ Lateral epikondilit tanısı genellikle klinik olarak konulur. Dirence karşı el bileği dorsifleksiyonu yapılması, lateral epikondil üzerine basınç uygulanması ve bir cismin el ile sıkıca kavranması ile ön kola yayılan ağrı oluşur. Lateral epikondilit tedavisinde birçok yöntem kullanılmaktadır. Sadece bekle-gör ${ }^{[2]}$ steroid olmayan antienflamatuvar ilaç (SOAEI),${ }^{[3]}$ breys, ${ }^{[4]}$ egzersiz, ${ }^{[5-8]}$ cyriax fizyoterapi (Mill manevrası ile birlikte yap1lan derin transvers friksiyon masaj1), ${ }^{[8]}$ akupunktur, ${ }^{[9]}$ proloterapi ${ }^{[10]}$ botulinum toksin enjeksiyonu ${ }^{[11]}$ otolog kan enjeksiyonu, ${ }^{[12]}$ fizyoterapi (FT),${ }^{[2,13]}$ lokal steroid enjeksiyonu, ${ }^{[2,3,12-14]}$ ekstrakorporeal şok dalga tedavisi $(\text { ESWT })^{[13-16]}$ ve tenotomi ${ }^{[15]}$ en yaygin kullanılan tedavi yöntemleridir. Bazı yazarlar ESWT’nin lateral epikondilit tedavisinde etkili olmadığını belirtirken ${ }^{[17]}$ bazı- $^{-}$ ları da lokal steroid enjeksiyonunun ESWT'den daha etkili olduğunu belirtmiştir. ${ }^{[14]}$ Bazı yazarlar lokal enjeksiyonun kısa dönemde etkili olduğunu ancak uzun dönemde etkili olmadığını buna karşın FT ve bekle-gör tedavisinin uzun dönemde etkili olduğunu belirtmişlerdir. $^{[2]}$ Lateral epikondilit tedavisinde bu kadar çok çeşitlilikte tedavi yöntemi olmasına karşın hangisinin en etkili ve başarılı olduğu konusunda bir görüş birliği yoktur.
Amacımız randomize prospektif klinik çalışma ile lateral epikondilit tedavisinde kullanılan ESWT, FT ve lokal steroid enjeksiyonu (E) yöntemlerinin birbirlerine üstünlüğünü karşılaştırmaktır.

\section{HASTALAR VE YÖNTEMLER}

Ocak 2013 - Aralık 2013 tarihleri arasında Kastamonu Fizik Tedavi ve Rehabilitasyon Merkezi ve Bafra Devlet Hastanesi Fiziksel Tip ve Rehabilitasyon Kliniği'ne dirsek ağrısı ile başvuran ve fizik muayenede epikondil üzerine basmakla hassasiyet, dirence karşı el bilek ekstansiyonu ve el bilek ekstansörlerinin gerilmesi sırasında ağrı varlığ 1 ile lateral epikondilit tanısı konulan 90 hasta değerlendirmeye alındı. Bunlardan hastalık süresi 1-10 ay olan ve daha önce herhangi bir fizik tedavi yöntemi (ESWT, FT) ile tedavi edilmemiş, lokal steroid enjeksiyonu yapılmamış veya SOAEİ kullanmamış olan 59 hasta (34 erkek, 25 kadın; ortalama yaş 46.4 yıl; dağılım 35-60 yıl) çalışmaya dahil edilirken, servikal bölge ve omuz patolojileri nedeniyle yansıyan ağrısı, dirsek osteoartriti, geçirilmiş dirsek kırığ bozukluğu, nörolojik defisit, malignite, kalp pili veya enflamatuvar hastalık öyküsü olan ve antikoagülan kullanan 14 hasta ile takip sirasında kontrollere gelmeyen 17 hasta çalışma dışı bırakıldı. Çalışma kriterlerine uyan hastaların ilk değerlendirmesi yapıldıktan sonra hastalar ESWT, FT ve E grubu olmak üzere üç gruba ayrıldı (Şekil 1).

Çalışma için gerekli etik kurul izni Ondokuz Mayıs Üniversitesi Tıp Fakültesi Etik Kurulu'ndan alındı

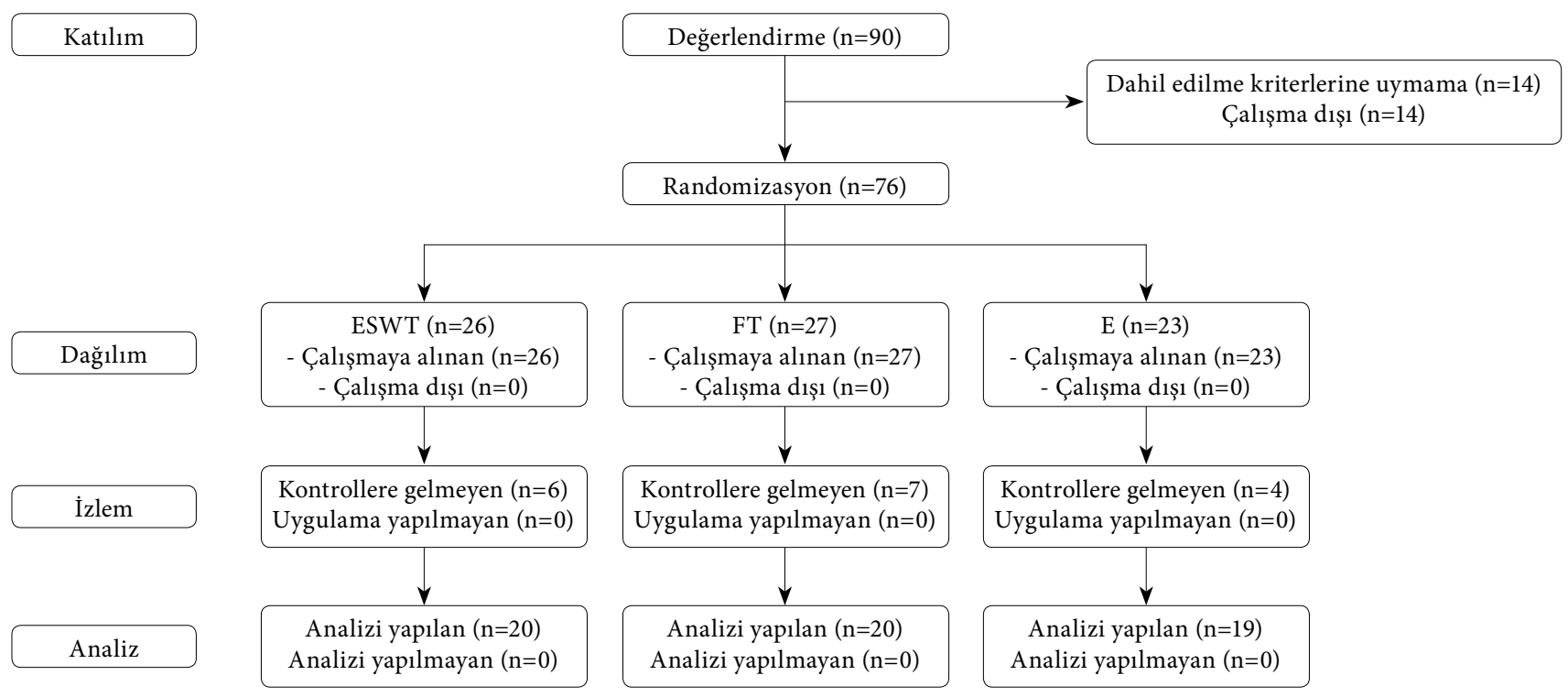

Şekil 1. Akışş şeması. ESWT: Ekstrakorporeal şok dalga tedavisi; FT: Fizyoterapi; E: Enjeksiyon. 
(2012-271). Hastalar yapılacak işlem hakkında bilgilendirildi ve bilgilendirilmiş hasta onamları alındı. Çalışma Helsinki Beyannamesi’ne uygun şekilde yürütüldü. Çalışma öncesinde hasta sayısının belirlenmesi için benzer çalışmalardan yararlanılarak güç analizi yapıldı. Birincil tip hata $\alpha=0.05$, ikincil tip hata $\beta=0.2$ olacak şekilde $\% 95$ güven aralığ $(\mathrm{GA})$ 'nda \pm 4 standart sapma (SS) ile her gruba düşecek en az hasta sayısı 16 olarak hesaplandı. Hastalara çalışma ile ilgili bilgiler verildi ve bilgilendirilmiş hasta onamları alındı. Başlangıçta tüm hastaların demografik verileri, görsel analog ölçeği (GAÖ) ile ölçülen ağrı skorları, memnuniyet durumları (memnun-memnun değil), el kavrama güçleri (Jamar hidrolik dinamometre ile üç ölçüm ortalaması alındı), (Sammons Preston, Inc., Bolingbrook, IL, USA) lateral epikondil üzerine basmakla oluşan ağrı (var-yok), Thomson ve sandalye kaldırma testleri yapıldı. Sandalye kaldırma testi için omuz 60 derece fleksiyonda, dirsek tam ekstansiyonda iken hastadan $3.5 \mathrm{~kg}$ ağırlığında bir su şişesini kaldırması istendi. Sonuçlar pozitif veya negatif olarak kaydedildi. Aynı değerlendirmeler üçüncü hafta, altıncı hafta ve 12 . haftada tekrar aynı araştırmacı tarafından yapılarak kaydedildi. Hastalara tedavi ve kontroller süresince ağrıyı artıracak aktivitelerden kaçınmaları söylendi ve herhangi bir ilaç, breys ve egzersiz verilmedi. Çalışma süresince tedavi uygulanan hiçbir hastada yan etki gözlenmedi. On ikinci haftanın sonunda, uygulanan tedaviler ile şikayetleri geçmeyen hastalara diğer tedavi yöntemleri uygulandı.

\section{Tedavi protokolii}

ESWT grubu: 1.8 bar, $10.0 \mathrm{~Hz}, 2000$ atım, bir gün/hafta toplam üç hafta (ShockMaster 500, Uniphy Elektromedizin, Hennigsdorf, Almanya, 2010).

Fizyoterapi grubu: 20 dakika sicak uygulama, $1.5 \mathrm{watt} / \mathrm{cm}^{2}, 5$ dakika ultrason, 20 dakika konvansiyonel transkütanöz elektriksel sinir stimülasyonu (TENS), beş gün/hafta, toplam üç hafta (Intelect Advanced, Chattanooga Group, Hixson, ABD, 2008).
Enjeksiyon grubu: Ağrılı epikondil bölgesine steril şartlarda tek doz $0.5 \mathrm{~mL}$ kortikosteroid (betametazon dipropianat $6.43 \mathrm{mg}$, betametazon sodyum fosfat $2.63 \mathrm{mg}$ ) ve $0.5 \mathrm{~mL}$ lokal anestezik (\%2 lidokain, epinefrin) karışımı steril şartlarda uyguland.

\section{İstatistiksel analiz}

İstatistiksel analiz için Erciyes Üniversitesi Tip Fakültesi Biyoistatistik Anabilim Dalı'nda lisansl1 olarak bulunan IBM SPSS 22.0 versiyon (IBM Corporation, Armonk, N.Y., USA) yazılım programı kullanıldı. Normal dağılan veriler için ortalama, standart sapma, normal dağılım göstermeyen veriler için medyan, 25. ve 75. persentil değeri verildi. Yaşın gruplar arası karşılaştırılması için tek yönlü varyans analizi, cinsiyet, dominant el ve hastalıklı kol verilerinin gruplar arası karşılaştırılması için ki-kare testi, hastalık süresinin gruplar arası karşılaştırılması için Kruskal Wallis testleri yapıldı. Görsel analog ölçeği ve el kavrama gücü verilerinin zamana göre $(0,3,6$. ve 12. hafta) karşılaştırması için Friedman, palpasyonla ağrı, Thompson testi, sandalye kaldırma testi ve hasta memnuniyeti için gruplar arası karşılaştırmalarda ki-kare, zamana göre karşılaştırmalarda Cochran testi kullanıldı. Görsel analog ölçeği ve el kavrama gücü için başlangıç (0) değerlerinden 3, 6 . ve 12. hafta değerleri çıkartılarak farklar bulundu. Başlangıç-üçüncü hafta (0-3), başlangıç-altıncı hafta (0-6) ve başlangıç-12. hafta (0-12) farklarının gruplar arasında karşılaştırılması için Kruskal Wallis testi kullanıldı. İstatistiksel anlamlılık düzeyi için $\mathrm{p}<0.05$ alind1.

\section{BULGULAR}

Hastaların demografik özellikleri Tablo 1'de verilmiştir. Her üç gruptaki katılımcılar arasında yaş, cinsiyet, dominant el, hastalıklı el ve hastalık süresi açısından anlamlı fark yoktu.

Tablo 1. Demografik veriler

\begin{tabular}{|c|c|c|c|c|c|c|c|c|c|c|c|c|c|c|c|c|}
\hline & \multicolumn{5}{|c|}{ Ekstrakorporeal şok dalga tedavisi grubu } & \multicolumn{5}{|c|}{ Fizyoterapi grubu } & \multicolumn{5}{|c|}{ Enjeksiyon grubu } & \multirow[b]{2}{*}{$p$} \\
\hline & Sayı & Yüzde & Ort. \pm SS & Medyan & $\mathrm{P}(25)-\mathrm{P}(75)$ & Sayı & Yüzde & Ort. \pm SS & Medyan & $\mathrm{P}(25)-\mathrm{P}(75)$ & Sayı & Yüzde & Ort. \pm SS & Medyan & $\mathrm{P}(25)-\mathrm{P}(75)$ & \\
\hline Yaş (yıl) & & & $47.95 \pm 7.36$ & & & & & $47.65 \pm 6.85$ & & & & & $43.58 \pm 7.49$ & & & 0.120 \\
\hline \multicolumn{17}{|l|}{ Cinsiyet } \\
\hline Erkek & 9 & 45 & & & & 14 & 70 & & & & 11 & 58 & & & & 0.278 \\
\hline Kadin & 11 & 55 & & & & 6 & 30 & & & & 8 & 42 & & & & \\
\hline \multicolumn{17}{|l|}{ Dominant el } \\
\hline Sağ & 20 & 100 & & & & 17 & 85 & & & & 16 & 84 & & & & 0.180 \\
\hline Sol & 0 & 0 & & & & 3 & 15 & & & & 3 & 16 & & & & \\
\hline \multicolumn{17}{|l|}{ Hasta kol } \\
\hline Sağ & 13 & 65 & & & & 11 & 55 & & & & 13 & 68 & & & & 0.664 \\
\hline Sol & 7 & 35 & & & & 9 & 45 & & & & 6 & 32 & & & & \\
\hline Hastalık & & & & & & & & & & & & & & & & \\
\hline süresi (ay) & & & & 3.00 & $1.00-10.00$ & & & & 2.50 & $1.00-6.00$ & & & & 3.00 & $2.00-7.00$ & 0.929 \\
\hline
\end{tabular}


Tablo 2. Görsel analog ölçeği ve el kavrama gücü verileri

\begin{tabular}{|c|c|c|c|c|c|c|c|c|c|c|}
\hline & \multirow[b]{2}{*}{$\mathrm{n}$} & \multicolumn{2}{|c|}{ Başlangıç } & \multicolumn{2}{|c|}{ 3. Hafta } & \multicolumn{2}{|c|}{ 6. Hafta } & \multicolumn{2}{|c|}{ 12. Hafta } & \multirow[b]{2}{*}{$p$} \\
\hline & & Medyan & $\mathrm{p}(25)-\mathrm{p}(75)$ & Medyan & $\mathrm{p}(25)-\mathrm{p}(75)$ & Medyan & $\mathrm{p}(25)-\mathrm{p}(75)$ & Medyan & $\mathrm{p}(25)-\mathrm{p}(75)$ & \\
\hline \multicolumn{11}{|c|}{ Görsel analog ölçeği } \\
\hline ESWT & 20 & 55.00 & $50.00-67.50^{*}$,†, & 25.00 & $0.00-48.75^{\star}$ & 0.00 & $0.00-7.50 \dagger$ & 0.00 & $0.00-0.00 \ddagger$ & $<0.001$ \\
\hline Fizyoterapi & 20 & 43.00 & $32.50-58.75^{*}, \dagger$ † & 0.00 & $0.00-33.75^{*}$ & 0.00 & $0.00-0.00 \dagger$ & 0.00 & $0.00-0.00 \ddagger$ & $<0.001$ \\
\hline Enjeksiyon & 19 & 60.00 & $40.00-70.00^{*}$,†, & 11.00 & $0.00-53.00^{*}$ & 0.00 & $0.00-22.00 \dagger$ & 0.00 & $0.00-10.00 \ddagger$ & $<0.001$ \\
\hline \multicolumn{11}{|c|}{ El kavrama gücü } \\
\hline ESWT & 20 & 26.67 & 18.67-32.34*,†, & 28.34 & $24.17-37.50^{*}$ & 30.67 & $24.67-37.17 \dagger$ & 32.17 & $26.17-38.34 \ddagger$ & $<0.001$ \\
\hline Fizyoterapi & 20 & 26.00 & $18.67-38.42 \ddagger$ & 24.50 & $20.00-41.67 \S$ & 27.00 & $20.57-40.31$ & 27.82 & $20.92-44.17 \ddagger, \S$ & $<0.001$ \\
\hline Enjeksiyon & 19 & 31.33 & $27.00-40.00 \dagger$ † & 40.00 & $28.00-46.67$ & 39.33 & $27.66-48.00 \dagger$ & 39.33 & 27.66-48.00末 & $<0.001$ \\
\hline
\end{tabular}

P(25): 25. persentil; P(75): 75. persentil; GAÖ: Görsel analog ölçeği; ESWT: Ekstrakorporeal şok dalga tedavisi; * Başlangıç - 3. hafta arasında istatistiksel olarak anlamlı fark var $(\mathrm{p}<0.05)$; † Başlangıç - 6. hafta arasında istatistiksel olarak anlamlı fark var $(\mathrm{p}<0.05)$; $\ddagger$ Başlangıç - 12. hafta arasında istatistiksel olarak anlamlı fark var $(\mathrm{p}<0.05)$; $§ 3$. - 12. hafta arasında istatistiksel olarak anlamlı fark var $(\mathrm{p}<0.05)$; Sonuçlar medyan 25 . ve 75 . persentil olarak verilmiştir.

Görsel analog ölçeği değerleri her üç grupta başlangıca kıyasla 3, 6. ve 12. haftalarda istatistiksel olarak anlamlı düzeyde azaldı (Tablo 2).

El kavrama gücü ESWT grubunda başlangıca kıyasla 3, 6. ve 12. haftalarda istatistiksel olarak anlamlı düzeyde arttı. FT grubunda başlangıca kıyasla 12. haftada, ayrica 3. hafta ile 12. hafta arasında istatistiksel olarak anlamlı artış gözlendi. E grubunda başlangıca kıyasla 6. haftada ve başlangıca kıyasla 12 . haftada istatistiksel olarak anlamlı artış gözlendi (Tablo 2).

Görsel analog ölçeği ve el kavrama gücü için her üç grupta başlangıç değerinden 3. hafta, 6 . hafta ve 12 . hafta değerleri çıkartılarak aradaki farklar bulundu. Başlangıç - 3. hafta (0-3), başlangıç - 6. hafta (0-6) ve başlangıç - 12. hafta (0-12) arasındaki farklar ESWT, FT ve E grupları arasında karşılaştırıldığında istatistiksel olarak anlamlı fark bulunmadı (Tablo 3).

Palpasyonla ağrı, Thomson testi ve sandalye kaldırma testleri başlangıca kıyasla 3, 6. ve 12. haftalarda anlamlı oranda düzelme gösterdi. Ayrıca 3. haftaya kıyasla 12. haftada anlamlı oranda düzelme gözlendi (Tablo 4). Ancak ESWT, FT ve E grupları aynı zaman dilimleri içerisinde karşılaştırıldığında aralarında anlamlı fark bulunmadı ( $>0.05)$ (Tablo 4).
Hasta memnuniyeti başlangıca kıyasla 3, 6. ve 12. haftalarda her üç grup için de anlamlı oranda artış gösterdi, ancak tedavi grupları arasında istatistiksel olarak anlamlı fark bulunmadı (Tablo 5).

\section{TARTIŞMA}

Lateral epikondilit hastalığının tedavisinde birçok tedavi yöntemi kullanılmakla beraber en etkili yöntemin hangisi olduğu tartışmalıdır. Çalışmamızda en sık kullanılan üç tedavi yönteminden (ESWT, FT ve lokal enjeksiyon yöntemleri) hangisinin en etkili olduğunun bulunması amaçlandı, ancak 12 haftalık izlem sonucunda bu yöntemlerin tedavide anlamlı oranda etkili olduğu ancak birbirlerine üstünlükleri olmadığ 1 görüldü. Çalışmaya dahil edilen hastaların yaş dağılımı ve hastalığın dominant elde olması literatür ile uyumlu bulundu. ${ }^{[1]}$

Çalışmalarda lokal steroid enjeksiyonu uygulamasının, ağrı azalması, global iyileşme ve el kavrama kuvveti üzerine olumlu etkisinin sadece 6. haftaya kadar olduğu yönünde bir görüş birliği vardır. ${ }^{[18-20]}$ Hay ve ark.nın, ${ }^{[21]}$ lokal steroid enjeksiyonu ile basit analjezik ve plasebo kullanımının lateral epikondiler ağrıya olan etkilerini inceledikleri çalışmalarında 4. haftada lokal steroid enjeksiyonu yapılan grupta

Tablo 3. Görsel analog ölçeği ve el kavrama gücü değişimleri

\begin{tabular}{|c|c|c|c|c|c|c|c|c|c|c|}
\hline & \multirow[b]{2}{*}{$\mathrm{n}$} & \multicolumn{3}{|c|}{ 0-3. Hafta } & \multicolumn{3}{|c|}{$0-6$. Hafta } & \multicolumn{3}{|c|}{ 0-12. Hafta } \\
\hline & & Medyan & $\mathrm{p}(25)-\mathrm{p}(75)$ & $p$ & Medyan & $\mathrm{p}(25)-\mathrm{p}(75)$ & $p$ & Medyan & $\mathrm{p}(25)-\mathrm{p}(75)$ & $p$ \\
\hline \multicolumn{11}{|c|}{ Görsel analog ölçeği } \\
\hline ESWT & 20 & 30.00 & $20.00-40.00$ & & 50.00 & $40.00-60.00$ & & 50.00 & $40.00-60.00)$ & \\
\hline Fizyoterapi & 20 & 30.00 & $10.00-47.50\}$ & 0.416 & 40.00 & $22.50-53.75$ & 0.228 & 40.00 & $22.50-53.75\}$ & 0.100 \\
\hline Enjeksiyon & 19 & 34.00 & $16.00-50.00 J$ & & 40.00 & $34.00-50.00$ & & 47.00 & $34.00-60.00 J$ & \\
\hline \multicolumn{11}{|c|}{ El kavrama gücü } \\
\hline ESWT & 20 & -4.50 & $-8.35--0.58$ & & -3.98 & $-8.66--0.41$ & & -5.00 & $-10.84--2.42$ ) & \\
\hline Fizyoterapi & 20 & -1.35 & $-3.92-0.50$ & 0.077 & -2.67 & $-6.75-0.26$ & 0.542 & -3.38 & $-7.92--0.33\}$ & 0.703 \\
\hline Enjeksiyon & 19 & -4.66 & $-10.67-0.00$ & & -5.00 & $-12.67--0.67$ & & -6.00 & $-12.00--1.00\}$ & \\
\hline
\end{tabular}

P(25): 25. persentil; P(75): 75. persentil; ESWT: Ekstrakorporeal şok dalga tedavisi; Sonuçlar medyan 25. ve 75. persentil olarak verilmiştir. 

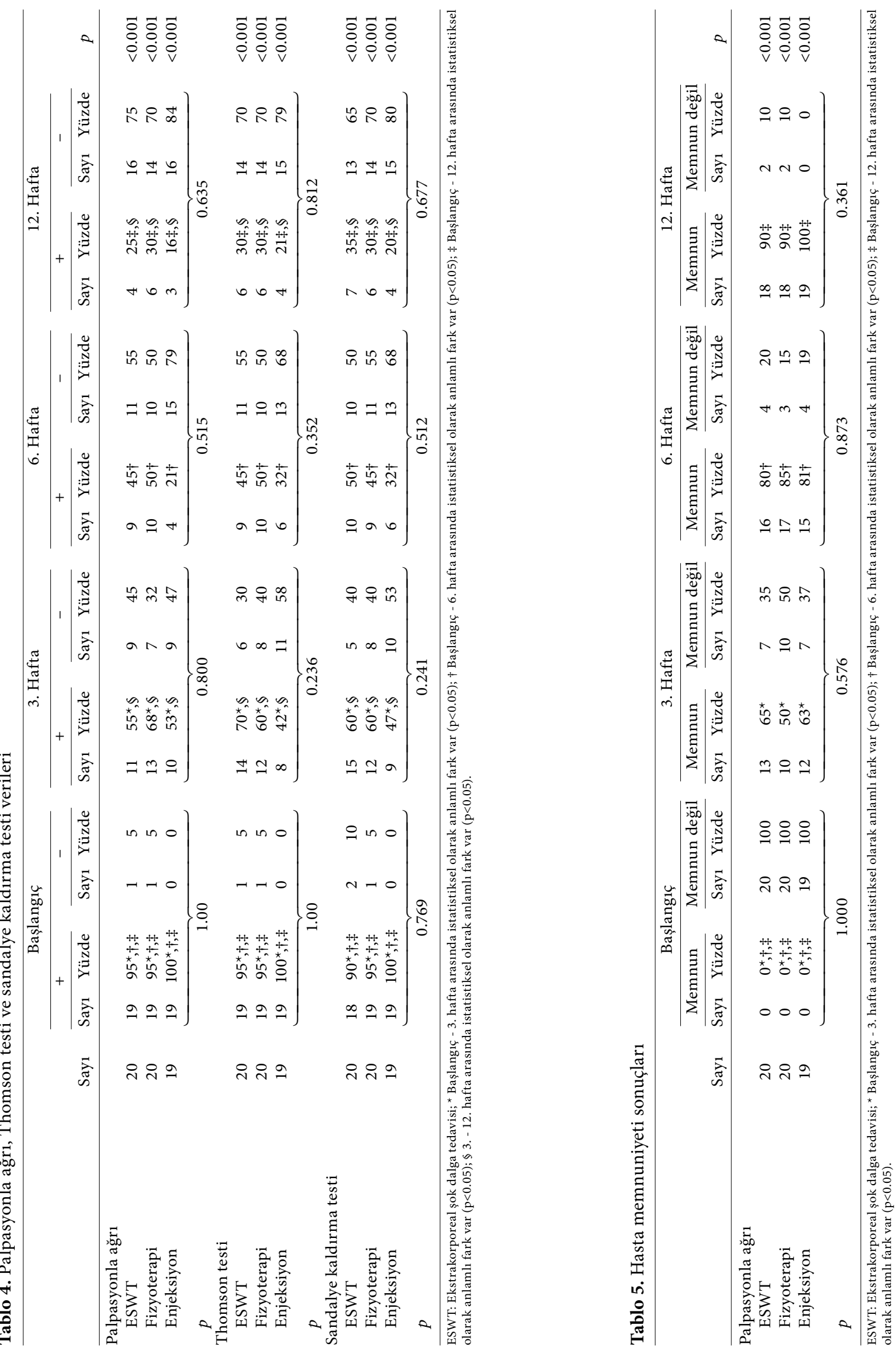
diğer gruplara kıyasla istatistiksel olarak daha iyi sonuçlar elde edildiği belirtilmiştir. Smidt ve ark., ${ }^{[22]}$ lokal steroid enjeksiyonu, FT ve bekle-gör yöntemlerini karşılaştırmış, steroid grubunun 6 . haftada ağrı ve hasta memnuniyeti açısından diğer tedavi gruplarına kıyasla en iyi sonucu verdiğini belirtmişlerdir. Verhaar ve ark. ${ }^{[18]}$ lokal enjeksiyonun erken dönemde etkili olduğunu ancak uzun dönemde cyriax FT'den farklı olmadığını bildirmişlerdir. Altay ve ark. ${ }^{[23]}$ 120 hastada lokal anestezik ve lokal steroid enjeksiyonu yöntemlerini karşılaştırmış ve birinci yıl sonunda her iki gruptaki hastaların büyük çoğunluğunda ağrı şikayetlerinin tamamen geçtiğini bildirmişlerdir. Tonks ve ark., ${ }^{[24]}$ lokal steroid enjeksiyonu, FT ve lokal steroid enjeksiyonuna ek olarak FT ve izleme yöntemlerini karşılaştırmış 7. haftada sadece lokal steroid enjeksiyonu yapılan grubun diğer üç gruba kıyasla daha iyi sonuçlar verdiğini belirtmişlerdir. Bisset ve ark. $^{[2,25]}$ steroid enjeksiyonu tedavisinin altı haftaya kadar en etkili yöntem olduğunu ancak bu yöntemin nüks oranının yüksek olduğunu belirtmişlerdir. Okçu ve ark. ${ }^{[26]}$ enjeksiyon yöntemlerini karşılaştırdıkları bir çalışmada yaygın hematom oluşturan 'peppering' tekniğinin uzun dönemde de lateral epikondilit tedavisinde etkili olduğunu bildirmişlerdir. Coombes ve ark. $^{[27]}$ ise fizik tedavi ile kombine steroid enjeksiyonunun sadece steroid enjeksiyonuna kıyasla daha etkili olduğunu belirtmişlerdir. Bizim çalışmamızda steroid enjeksiyonu grubunda GAÖ, el kavrama kuvveti, palpasyonla ağrı, hasta memnuniyeti, Thomson ve sandalye kaldırma testi verileri 12 . haftaya dek olumlu yönde gelişim gösterdi. Enjeksiyonda epinefrinli lidokain kullanmanın steroidin enjeksiyon bölgesindeki lokal etkisini artırdığını dolayısıyla tedavinin uzun dönemde etkinliğini korumasına bunun katkı sağlamış olabileceğini düşünmekteyiz. Mevcut çalışmalarda kabul edilen steroidlerin 6 . haftaya kadar etkin olduğu görüşünü destekler nitelikte bizim çalışmamızda da bu etki 12 . haftaya kadar sürdü.

Lateral epikondilit tedavisinde ESWT'nin etkinliği çeşitli çalışmalarda farklı bulunmuş ve bunun uygulanan atım sayısı ile ilişkili olabileceği belirtilmiştir. Radwan ve ark. ${ }^{[15]}$ kronik lateral epikondilitli hastalarda yüksek enerjili ESWT ile tenotominin etkinliğini karşılaştırdıkları çalışmalarında, üçüncü ayda ESWT grubunda $\% 65.5$, tenotomi grubunda ise $\% 74.1$ olumlu gelişme elde etmişler ve bu sonuçlar ışı̆̆ında ESWT'nin cerrahi düşünülen olgularda kullanışlı bir non-invazif tedavi yöntemi olabileceğini belirtmişlerdir. Ko ve ark. $^{[28]}$ ESWT uyguladıkları 35 hastanın 12 haftalık izlemi sonucunda \%13.2'sinde mükemmel, \%44.7'sinde iyi, \%36.8'inde kabul edilebilir, \%5.3'ünde ise başlan- gıçla aynı sonuçlar elde etmişlerdir. Wang ve Chen ${ }^{[29]}$ de benzer bir hasta grubunda ESWT ile \%29.5 anlamlı iyileşme \%6.8 hafif iyileşme elde etmișler ve ESWT'nin lateral epikondilitte etkili ve güvenilir bir tedavi yöntemi olduğunu belirtmişlerdir. Gündüz ve ark. ${ }^{[13]}$ ESWT, steroid enjeksiyonu ve fizyoterapi uygulanan üç grubu karşılaştırdıkları çalışmalarında, ESWT ile elde edilen el kavrama kuvvetindeki artışın daha uzun sürdügünü belirtmişlerdir. Özkut ve ark. ${ }^{\left[{ }^{[0]}\right.}$ konservatif tedaviden fayda görmeyen hastalarda ESWT ile olumlu gelişmeler elde edildiğini ve cerrahi düşünülmeyen hastalarda ESWT’nin alternatif bir tedavi yöntemi olduğunu belirtmişlerdir. Lee ve ark. ${ }^{[31]}$ ESWT'nin lokal steroid enjeksiyonu kadar etkili olduğunu ileri sürerken, Devrimsel ve ark. ${ }^{[32]}$ ESWT'nin lazer tedavisine kıyasla daha etkili olduğunu bildirmişlerdir. Buna karşın Buchbinder ve ark.nın ${ }^{[33]} 2005$ yılında yayınladıkları derlemede, lateral epikondilitli 1006 hastanın değerlendirildiği plasebo kontrollü dokuz çalışmada, ESWT'nin ağrı ve dirsek fonksiyonlarına çok az katkı sağladığı veya hiç etkisi olmadığını, 93 olguluk bir çalışmada ise steroid enjeksiyonunun ESWT'den daha etkili olduğunu bildirmişlerdir. Çalışma sonuçlarının birbirinden farklı olmasını öncelikle kullanılan ESWT cihazlarının farklı modeller olmasına ve uygulanan tedavi protokollerinin standart olmamasina bağlayabiliriz. Örneğin Rompe ve ark. ${ }^{[34,35]}$ düşük doz ve yüksek doz ESWT uygulamasını karşılaştırmışlar ve düşük dozun ağrıyı azaltmada etkili olmadığını belirtmişlerdir. Speed ve ark. ${ }^{[36]}$ ise 1500 atım/seans ayda bir olmak üzere toplam üç seans gibi 1lımlı dozlarda yapılan ESWT tedavisinin plasebo etkisi yaptığını belirtmiştir. Biz, çalışma sonuçlarımız ışı̆̆ında ESWT'nin lateral epikondilit tedavisinde önemli bir yeri olduğunu söyleyebiliriz. Kendi tedavi protokolümüzde 2000 atım/hafta olmak üzere toplam 6000 atım kullandık ve maksimal hassasiyet noktasında kalabilmek adına lokal anestezik kullanmadık. Sonuçta, lokal steroid enjeksiyonu ve FT grubu ile benzer sonuçlar elde ettik. Gelecek çalışmalarda cihaz ve protokollerin standardize edilmesi ESWT'nin etkinliğini daha net anlamamıza yardımcı olacaktır.

Lateral epikondilit tedavisinde FT'nin etkinliği halen tartışma konusu olmaya devam etmektedir. Gündüz ve ark.nın ${ }^{[13]}$ FT, ESWT ve E tedavi yöntemlerini karşılaştırdıkları çalışmada GAÖ skorları ve el kavrama kuvveti gelişiminin üç grupta da benzer olduğu belirtilmiştir. Binder ve ark. ${ }^{[37]}$ ultrason tedavisinin lateral epikondilit tedavisinde plaseboya kıyasla anlamlı oranda iyileşme sağladığını belirtmişlerdir. Bisset ve ark. ${ }^{[2]}$ fizyoterapinin 6. haftadan sonra kortikosteroid enjeksiyonuna kıyasla daha 
olumlu sonuçlar sağladığını ancak bekle-gör yöntemine üstün olmadığını belirtmişlerdir. ${ }^{[2]}$ Bir diğer çalışmada düşük seviyeli lazer terapinin lateral epikondilit tedavisinde uygun dozda kullanıldığında etkili olduğu belirtilmiştir. ${ }^{[38]}$ Bununla beraber ağr1nın egzersiz verilen hastalarda, egzersiz tedavisi almayanlara kıyasla daha fazla azald $\breve{g ̆ g}_{1},{ }^{[6]}$ gözetimli egzersiz programlarının cyriax FT'ye kıyasla daha etkili olduğu belirtilmiştir. ${ }^{[8]}$ Buna karşı kronik lateral epikondilitli hastalarda pulse düşük yoğunluklu ultrason tedavisinin plaseboya üstün olmadığ ${ }_{1}{ }^{[39]}$ TENS'in ise anlamlı düzelme sağlamadığı belirtilmiştir. ${ }^{[40]}$ Struijs ve ark. ${ }^{[41]}$ çalışmalarında manipülasyon ile ultrasonla kombine friksiyon masajını kuvvet ve esneklik egzersizleri ile kombine ederek karş1laştırmış, 6. haftaya kadar manipülasyonun daha etkili olduğunu ileri sürmüşlerdir. Biz çalışmamızda kliniklerde yaygın olarak kullanılan ve pratik bir FT yöntemi olan sıcak su paketleriyle yüzeyel isı uygulaması, ultrason ve TENS kombinasyonunu kullandık. Sonuçlarımız bize sadece FT'nin de lateral epikondilit tedavisinde etkili sonuçlar verebileceğini göstermektedir.

Etik nedenlerle bekle-gör yönteminin kullanılamaması ve takip zorluğu nedeniyle tedavi etkinliğinin uzun dönem sonuçlarının değerlendirilememesi çalışmamızın kısıtlılığ

Sonuç olarak, bu çalışmada lateral epikondilit tedavisinde lokal steroid enjeksiyonu, ESWT ve FT yöntemlerinin sonuçları değerlendirilmiş, her üç tedavi yönteminin de 12 hafta sonunda anlamlı oranda etkili olduğu ancak tedavi yöntemlerinin birbirlerine üstünlüğünün olmadığı gözlenmiştir. Tedavi etkinliğinin uzun dönem sonuçlarının da karşılaştırıldığı benzer çalışmalara ihtiyaç vardır.

\section{Çıkar çakışması beyanı}

Yazarlar bu yazının hazırlanması ve yayınlanması aşamasında herhangi bir çıkar çakışması olmadığını beyan etmişlerdir.

\section{Finansman}

Yazarlar bu yazının araştırma ve yazarlık sürecinde herhangi bir finansal destek almadıklarını beyan etmişlerdir.

\section{KAYNAKLAR}

1. De Smedt T, de Jong A, Van Leemput W, Lieven D, Van Glabbeek F. Lateral epicondylitis in tennis: update on aetiology, biomechanics and treatment. Br J Sports Med 2007;41:816-9.

2. Bisset L, Beller E, Jull G, Brooks P, Darnell R, Vicenzino B. Mobilisation with movement and exercise, corticosteroid injection, or wait and see for tennis elbow: randomised trial. BMJ 2006;333:939.
3. Toker S, Kilinçoğlu V, Aksakalli E, Gülcan E, Ozkan K. Short-term results of treatment of tennis elbow with antiinflammatory drugs alone or in combination with local injection of a corticosteroid and anesthetic mixture. [Article in Turkish] Acta Orthop Traumatol Turc 2008;42:184-7.

4. Struijs PA, Korthals-de Bos IB, van Tulder MW, van Dijk CN, Bouter LM, Assendelft WJ. Cost effectiveness of brace, physiotherapy, or both for treatment of tennis elbow. Br J Sports Med 2006;40:637-43.

5. Park JY, Park HK, Choi JH, Moon ES, Kim BS, Kim WS, et al. Prospective evaluation of the effectiveness of a homebased program of isometric strengthening exercises: 12-month follow-up. Clin Orthop Surg 2010;2:173-8.

6. Peterson M, Butler S, Eriksson M, Svärdsudd K. A randomized controlled trial of exercise versus wait-list in chronic tennis elbow (lateral epicondylosis). Ups J Med Sci 2011;116:269-79.

7. Stasinopoulos D, Stasinopoulou K, Johnson MI. An exercise programme for the management of lateral elbow tendinopathy. Br J Sports Med 2005;39:944-7.

8. Viswas R, Ramachandran R, Korde Anantkumar P. Comparison of effectiveness of supervised exercise program and Cyriax physiotherapy in patients with tennis elbow (lateral epicondylitis): a randomized clinical trial. Scientific World Journal 2012;2012:939645.

9. Fink M, Wolkenstein E, Karst M, Gehrke A. Acupuncture in chronic epicondylitis: a randomized controlled trial. Rheumatology (Oxford) 2002;41:205-9.

10. Scarpone M, Rabago DP, Zgierska A, Arbogast G, Snell E. The efficacy of prolotherapy for lateral epicondylosis: a pilot study. Clin J Sport Med 2008;18:248-54.

11. Espandar R, Heidari P, Rasouli MR, Saadat S, Farzan M, Rostami M, et al. Use of anatomic measurement to guide injection of botulinum toxin for the management of chronic lateral epicondylitis: a randomized controlled trial. CMAJ 2010;182:768-73.

12. Jindal N, Gaury Y, Banshiwal RC, Lamoria R, Bachhal V. Comparison of short term results of single injection of autologous blood and steroid injection in tennis elbow: a prospective study. J Orthop Surg Res 2013;8:10.

13. Gündüz R, Malas FÜ, Borman P, Kocaoğlu S, Özçakar L. Physical therapy, corticosteroid injection, and extracorporeal shock wave treatment in lateral epicondylitis. Clinical and ultrasonographical comparison. Clin Rheumatol 2012;31:807-12.

14. Crowther MA, Bannister GC, Huma H, Rooker GD. A prospective, randomised study to compare extracorporeal shock-wave therapy and injection of steroid for the treatment of tennis elbow. J Bone Joint Surg [Br] 2002;84:678-9.

15. Radwan YA, ElSobhi G, Badawy WS, Reda A, Khalid S. Resistant tennis elbow: shock-wave therapy versus percutaneous tenotomy. Int Orthop 2008;32:671-7.

16. Spacca G, Necozione S, Cacchio A. Radial shock wave therapy for lateral epicondylitis: a prospective randomised controlled single-blind study. Eura Medicophys 2005;41:17-25.

17. Melikyan EY, Shahin E, Miles J, Bainbridge LC. Extracorporeal shock-wave treatment for tennis elbow. A randomised double-blind study. J Bone Joint Surg [Br] 2003;85:852-5. 
18. Verhaar JA, Walenkamp GH, van Mameren H, Kester AD, van der Linden AJ. Local corticosteroid injection versus Cyriax-type physiotherapy for tennis elbow. J Bone Joint Surg [Br] 1996;78:128-32.

19. Assendelft WJ, Hay EM, Adshead R, Bouter LM. Corticosteroid injections for lateral epicondylitis: a systematic overview. Br J Gen Pract 1996;46:209-16.

20. Smidt N, Assendelft WJ, van der Windt DA, Hay EM, Buchbinder R, Bouter LM. Corticosteroid injections for lateral epicondylitis: a systematic review. Pain 2002;96:23-40.

21. Hay EM, Paterson SM, Lewis M, Hosie G, Croft P. Pragmatic randomised controlled trial of local corticosteroid injection and naproxen for treatment of lateral epicondylitis of elbow in primary care. BMJ 1999;319:964-8.

22. Smidt N, van der Windt DA, Assendelft WJ, Devillé WL, Korthals-de Bos IB, Bouter LM. Corticosteroid injections, physiotherapy, or a wait-and-see policy for lateral epicondylitis: a randomised controlled trial. Lancet 2002;359:657-62.

23. Altay T, Günal I, Oztürk H. Local injection treatment for lateral epicondylitis. Clin Orthop Relat Res 2002;398:12730.

24. Tonks JH, Pai SK, Murali SR. Steroid injection therapy is the best conservative treatment for lateral epicondylitis: a prospective randomised controlled trial. Int J Clin Pract 2007;61:240-6.

25. Bisset L, Smidt N, Van der Windt DA, Bouter LM, Jull G, Brooks $\mathrm{P}$, et al. Conservative treatments for tennis elbow do subgroups of patients respond differently? Rheumatology (Oxford) 2007;46:1601-5.

26. Okçu G, Erkan S, Sentürk M, Ozalp RT, Yercan HS. Evaluation of injection techniques in the treatment of lateral epicondylitis: a prospective randomized clinical trial. Acta Orthop Traumatol Turc 2012;46:26-9.

27. Coombes BK, Bisset L, Connelly LB, Brooks P, Vicenzino B. Optimising corticosteroid injection for lateral epicondylalgia with the addition of physiotherapy: a protocol for a randomised control trial with placebo comparison. BMC Musculoskelet Disord 2009;10:76.

28. Ko JY, Chen HS, Chen LM. Treatment of lateral epicondylitis of the elbow with shock waves. Clin Orthop Relat Res 2001;387:60-7.

29. Wang CJ, Chen HS. Shock wave therapy for patients with lateral epicondylitis of the elbow: a one- to two-year followup study. Am J Sports Med 2002;30:422-5.
30. Ozkut AT, Kilinçoğlu V, Ozkan NK, Eren A, Ertaş M. Extracorporeal shock wave therapy in patients with lateral epicondylitis. [Article in Turkish] Acta Orthop Traumatol Turc 2007;41:207-10.

31. Lee SS, Kang S, Park NK, Lee CW, Song HS, Sohn MK, et al. Effectiveness of initial extracorporeal shock wave therapy on the newly diagnosed lateral or medial epicondylitis. Ann Rehabil Med 2012;36:681-7.

32. Devrimsel G, Küçükali Türkyılmaz A, Yıldırım M, Ulaşlı AM. A comparison of laser and extracorporeal shock wave therapies in treatment of lateral epicondylitis. Turk J Phys Med Rehab 2014;60:194-8.

33. Buchbinder R, Green SE, Youd JM, Assendelft WJ, Barnsley L, Smidt N. Shock wave therapy for lateral elbow pain. Cochrane Database Syst Rev 2005;4:003524.

34. Rompe JD, Hope C, Küllmer K, Heine J, Bürger R. Analgesic effect of extracorporeal shock-wave therapy on chronic tennis elbow. J Bone Joint Surg Br 1996;78:233-7.

35. Rompe JD, Hopf C, Küllmer K, Heine J, Bürger R, Nafe B. Low-energy extracorporal shock wave therapy for persistent tennis elbow. Int Orthop 1996;20:23-7.

36. Speed CA, Nichols D, Richards C, Humphreys H, Wies JT, Burnet S, et al. Extracorporeal shock wave therapy for lateral epicondylitis--a double blind randomised controlled trial. J Orthop Res 2002;20:895-8.

37. Binder A, Hodge G, Greenwood AM, Hazleman BL, Page Thomas DP. Is therapeutic ultrasound effective in treating soft tissue lesions? Br Med J (Clin Res Ed) 1985;290:512-4.

38. Bjordal JM, Lopes-Martins RA, Joensen J, Couppe C, Ljunggren AE, Stergioulas A, et al. A systematic review with procedural assessments and meta-analysis of low level laser therapy in lateral elbow tendinopathy (tennis elbow). BMC Musculoskelet Disord 2008;9:75.

39. D’Vaz AP, Ostor AJ, Speed CA, Jenner JR, Bradley M, Prevost AT, et al. Pulsed low-intensity ultrasound therapy for chronic lateral epicondylitis: a randomized controlled trial. Rheumatology (Oxford) 2006;45:566-70.

40. Chesterton LS, Lewis AM, Sim J, Mallen CD, Mason EE, Hay EM, et al. Transcutaneous electrical nerve stimulation as adjunct to primary care management for tennis elbow: pragmatic randomised controlled trial (TATE trial). BMJ. 2013;347:5160.

41. Struijs PA, Damen PJ, Bakker EW, Blankevoort L, Assendelft WJ, van Dijk CN. Manipulation of the wrist for management of lateral epicondylitis: a randomized pilot study. Phys Ther 2003;83:608-16. 